\title{
Fish oil and treatment of cancer cachexia
}

\author{
Attilio Giacosa $\cdot$ Mariangela Rondanelli
}

Published online: 15 March 2008

(c) Springer-Verlag 2008

\begin{abstract}
Cancer cachexia is a syndrome characterized by high prevalence and multifactorial etiology. The pathophysiology of cancer-induced weight loss is mainly due to failure of food intake and to various metabolic abnormalities, including hypermetabolism. Multiple biologic pathways are involved in this process, including proinflammatory cytokines, neuroendocrine hormones and tumour specific factors such as proteolysis inducing factor (PIF). As a result, a protein and energy depletion is observed that is greater than what would be expected based on the simple decrease of food intake and is associated with marked reduction of lean body mass (LBM). Therapy requires a multi-model approach with control of reduced food intake and of the metabolic abnormalities. Combination treatment with nutritional support and modulation of metabolic/inflammation changes is promising. In this regard, n-3 fatty acids in dose of at least $1.5 \mathrm{~g} /$ day for a prolonged time to advanced cancer patients with weight loss, are associated with an improvement of clinical, biological and functional parameters and with amelioration of quality of life.
\end{abstract}

Keywords Fish oil · Omega-3 · Fatty acids · Cancer cachexia

\footnotetext{
A. Giacosa

Policlinico of Monza, Milan, Italy

M. Rondanelli

ASP, University of Pavia, Pavia, Italy

A. Giacosa $(\bowtie)$

Department of Gastroenterology, Policlinico di Monza,

Monza, Italy

e-mail: attilio.giacosa@policlinicodimonza.it
}

\section{Introduction}

Wide alterations in carbohydrate, lipid, and protein metabolism in the tumor-bearing host have been previously documented. Cancer anorexia/cachexia is characterized by a shift in nutrient use from the growth and maintenance of muscle mass to processes that support the immune response and affect disease resistance [6]. These changes can result in an increased rate of muscle protein degradation and increase in acute-phase protein synthesis, with progressive depletion of lean body mass, with clinical evidence of cachexia. As a matter of fact, the majority of cancer patients experience weight loss as their disease progresses and in general weight loss is a major prognostic indicator of poor survival and impaired response to anti-neoplastic therapy.

Cancer cachexia is a multifactorial event and inflammation plays a relevant pathogenetic role. Studies have demonstrated that a variety of pro-inflammatory cytokines can directly lead to development of anorexia and metabolic changes and can be associated with the development of cachexia (Fig 1). In addition, the presence of a pro-inflammatory response (documented by an acute phase protein response) has been associated in a variety of human malignancies with accelerated weight loss, anorexia, hypermetabolism and a shortened duration of survival. Not surprisingly, conventional nutritional support whether in the form of oral feeding, enteral feeding, or parenteral nutrition has generally failed to either prolong survival or improve the outcome of conventional anti-neoplastic therapy. (Table 1)

\section{Fish oil and cancer cachexia}

In healthy individuals and in patients with cancer, the production of pro-inflammatory cytokines such as IL-6, 
Table 1 Clinical therapeutic agents for the treatment of cachexia (adapted from [1])

\begin{tabular}{|c|c|c|c|}
\hline Action site & Agent & $\begin{array}{l}\text { Cancer } \\
\text { cachexia }\end{array}$ & $\begin{array}{l}\text { Other cachexia- } \\
\text { causing diseases }\end{array}$ \\
\hline \multirow[t]{5}{*}{ Appetite stimulants } & Progestational agents & $\sqrt{ }$ & $\sqrt{ }$ \\
\hline & Cannabinoids & $\sqrt{ }$ & $\sqrt{ }$ \\
\hline & Olanzepine & $\sqrt{ }$ & $\sqrt{ }$ \\
\hline & Corticosteroids & $\sqrt{ }$ & \\
\hline & Ghrelin & $\sqrt{ }$ & $\sqrt{ }$ \\
\hline \multirow[t]{7}{*}{ Nutritional supplements } & Amino acids & $\sqrt{ }$ & $\sqrt{ }$ \\
\hline & Creatine & & $\sqrt{ }$ \\
\hline & $\begin{array}{l}\text { Polyunsaturated fatty acids: } \\
\quad \text { eicosapentaenoic acid (n-3) (fish oil) }\end{array}$ & $\sqrt{ }$ & $\sqrt{ }$ \\
\hline & Anabolic steroids & $\sqrt{ }$ & $\sqrt{ }$ \\
\hline & Insulin & & $\sqrt{ }$ \\
\hline & $\begin{array}{l}\text { Insulin-like growth factor, growth } \\
\text { hormone }\end{array}$ & $\sqrt{ }$ & $\sqrt{ }$ \\
\hline & $\beta$-adrenergic agonists & & \\
\hline \multicolumn{2}{|l|}{ Exercise } & $\sqrt{ }$ & $\sqrt{ }$ \\
\hline \multirow[t]{2}{*}{ Combination therapy } & $\begin{array}{l}\text { Exercise }+ \text { oral nutritional } \\
\text { supplementation }\end{array}$ & & $\sqrt{ }$ \\
\hline & $\begin{array}{l}\text { Anabolic steroids }+ \text { oral nutritional } \\
\text { supplementation }\end{array}$ & & $\sqrt{ }$ \\
\hline \multirow[t]{7}{*}{ Anti-inflammatory } & $\begin{array}{l}\text { Polyunsaturated fatty acids: } \\
\text { eicosapentaenoic acid (n-3) (fish oil) }\end{array}$ & $\sqrt{ }$ & $\sqrt{ }$ \\
\hline & Nonsteroidal anti-inflammatory agents & $\sqrt{ }$ & $\sqrt{ }$ \\
\hline & Macrolide antibiotics & $\sqrt{ }$ & \\
\hline & Cytokine inhibitors & $\sqrt{ }$ & $\sqrt{ }$ \\
\hline & Statins & & $\sqrt{ }$ \\
\hline & Thalidomide & $\sqrt{ }$ & \\
\hline & Pentoxyphylline & $\sqrt{ }$ & $\sqrt{ }$ \\
\hline
\end{tabular}

IL-1 and TNF can be down-regulated by the omega-3 polyunsaturated fatty acid, eicosapentaenoic acid (EPA). Furthermore, the effects of proteolisis inducing factor (PIF), a cachectic factor produced by cancer tissue, are also inhibited by EPA (Fig. 1).

In 1996, Wigmore et al. [11] evaluated the effects of EPA in 18 patients with cachexia due to unresectable

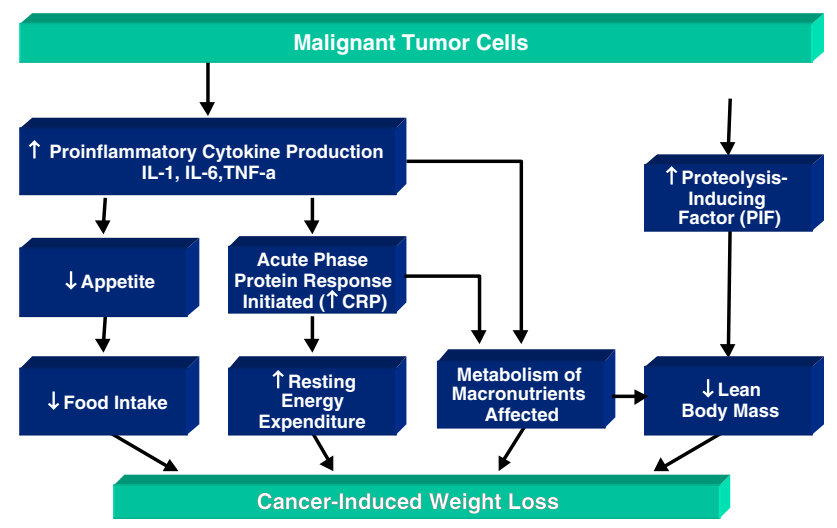

Fig. 1 Metabolic pathogenesis of cancer cachexia pancreatic cancer. The patients received approximately $12 \mathrm{~g}$ of fish oil per day ( $2 \mathrm{~g}$ of EPA per day) over a period of three months. This was associated with the arrest of cachexia in the majority of patients, with a small proportion of patients actually gaining weight. These findings markedly contrast with the natural history of pancreatic cancer in which patients progressively lose weight.

Barber et al. evaluated the effect of an oral nutritional supplement enriched with fish oil on weight loss in patients with advanced pancreatic cancer (Figs. 2, 3). After administration of the fish oil-enriched supplement, patients had a significant weight gain at both 3 (median $1 \mathrm{~kg}$, $P=0.024$ ) and 7 weeks (median $2 \mathrm{~kg}, P=0.033$ ). REE per $\mathrm{kg}$ body weight and per $\mathrm{kg}$ lean body mass fell significantly. Performance status and appetite were significantly improved at 3 weeks[2].

The positive effects of EPA rich nutritional supplements in the treatment of advanced pancreatic cancer with weight loss was subsequently confirmed by Fearon et al. [5] with evidence of lean body mass increase and increased quality of life after treatment for 2 months(Fig. 4). These results were obtained with post hoc dose response analysis which 


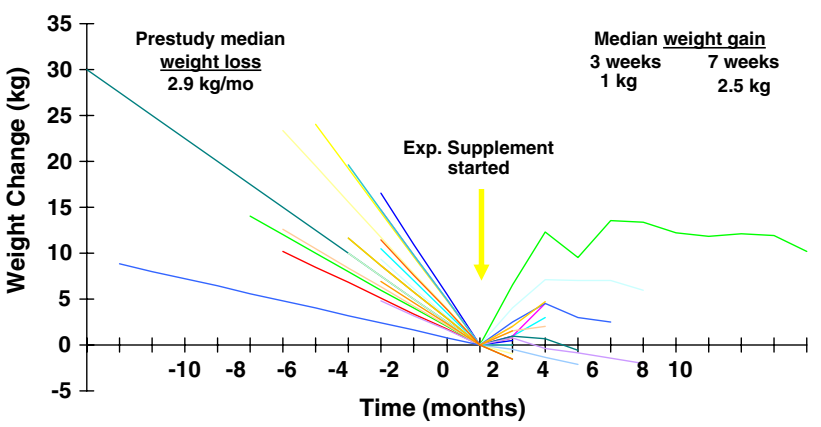

Fig. 2 Omega 3 enriched nutritional supplements in the treatment of cancer weight loss [2]
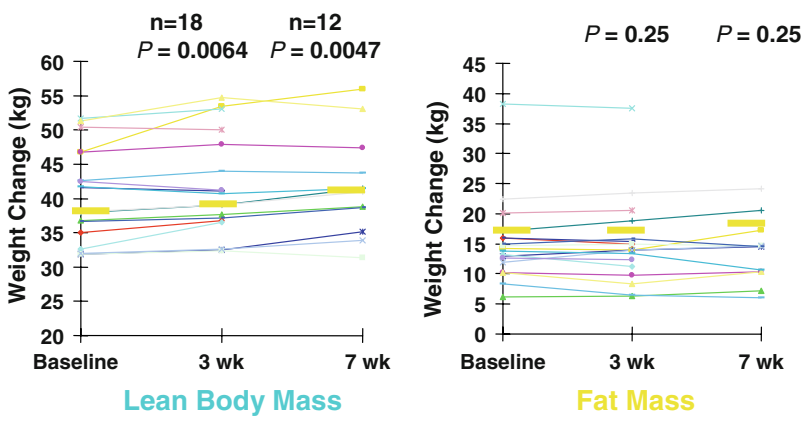

Fig. 3 Changes in body composition after treatment of cancer cachexia with omega 3 enriched nutritional supplements [2]

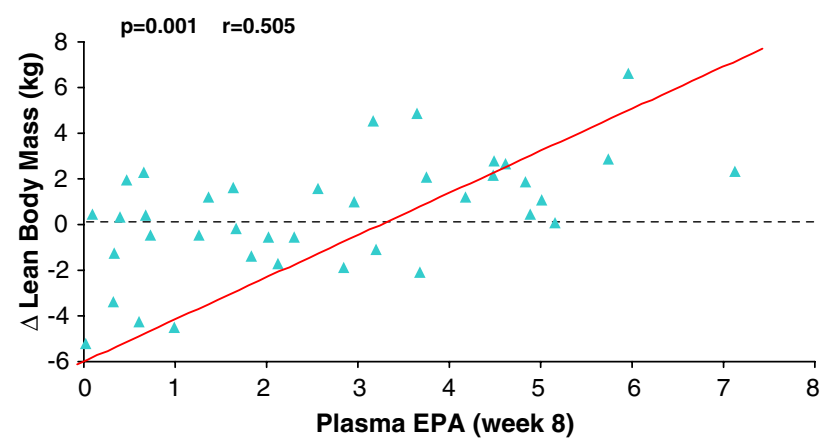

Fig. 4 Modifications of lean body mass according to changes in plasma EPA, after treatment with omega 3 FA enriched nutritional supplements of cancer cachexia [5]

showed that in order to achieve a net gain of body weight and lean body mass it was required a daily consumption of 1.5-2 cans of supplement enriched with $\mathrm{n}-3$ fatty acids and antioxidants, for two months (Fig. 5). This corresponds to $1.5-2 \mathrm{~g} /$ day of EPA and to $450-600 \mathrm{kcal} / \mathrm{day}$. A similar intake of nutritional supplement enriched with EPA was associated with a significant increase of

Physical acivity level (PAL) and of total energy expenditure (TEE), showing that patients with pancreatic

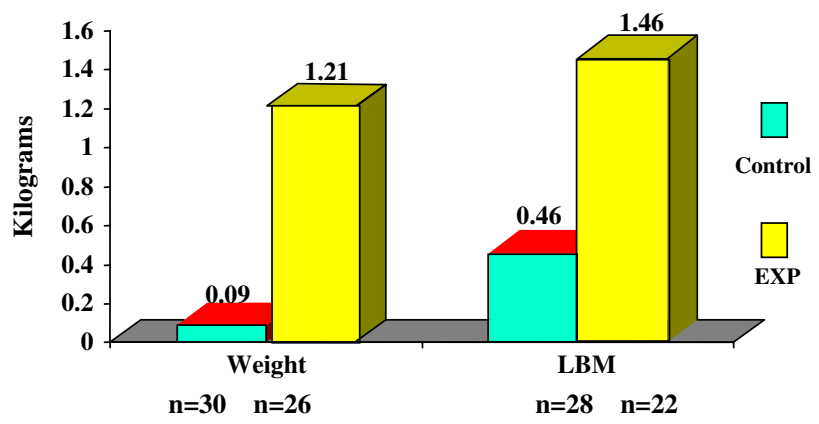

Fig. 5 Effect on weight and lean body mass in cachectic pancreatic cancer patients after treatment for 8 weeks with $1.5-2$ cans of omega 3 FA enriched nutritional supplements and in controls [5]

cancer could almost reach a normal sedentary level of activity [9] (Fig. 6).

These positive results were not confirmed by some of the subsequent studies [8] but this discrepancy could be explained by differences in the selection criteria of cancer patients and of the intervention protocol.

As a matter of fact, Colomer et al. [4] published recently a systematic review of the scientific literature on n.3 fatty acids, cancer and cachexia and concluded that administration of n-3 fatty acids in doses of at least $1.5 \mathrm{~g} /$ day for a prolonged period of time to patients with advanced cancer is associated with an improvement in clinical, biological and QoL parameters.

Also the parenteral administration of omega-3 fatty acids has been evaluated. Parenteral treatment with an emulsion with reduced content of n-6 fatty acids, increased share of MUFA and n-3 FA and supplemental vitamin E is well tolerated and modulates FA and leukotriene pattern, suggesting favourable anti-inflammatory effects and further clinical benefits [7].

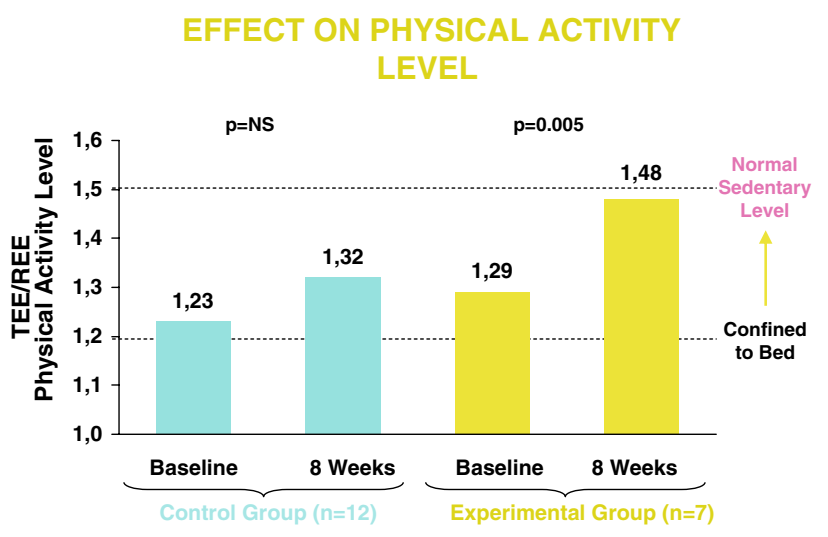

Moses et al. 2004 BJC;90:996

Fig. 6 Effect of nutritional supplements enriched with fish oil (vs. controls treated with similar supplements without fish oil) on the physical activity level of cancer patients with weight loss [9] 
New and interesting data are also available on the effects of fish oil on reduction of carcinogenesis and on reduction of the chemotherapy dose. Epidemiological studies have indicated that a high intake of saturated fat and/or animal fat increases the risk of colon and breast cancer. Laboratory and clinical investigations have shown a reduced risk of colon carcinogenesis after alimentation with omega-3 fatty acids, as found in fish oil. Mechanisms accounting for the antitumor effects are reduced levels of PGE(2) and inducible NO synthase as well as an increased lipid peroxidation,or transplantation inhibition with subsequent cell cycle arrest [10].

Additional interest in the field of cancer cachexia comes from the experience of Bossola et al. [3] who showed hyper-expression of m-RNA for ubiquitin and increased proteolithic activity of proteasome before weight loss in cancer patients. This experience could open a new research area in the field of early intervention and of prevention of cancer induced weight loss. Another problem which requires additional research is cancer anorexia, due to the frequent finding of reduced food intake in cancer patients and to the lack of powerful therapy to improve appetite and daily caloric intake.

\section{Conclusions}

Cancer induced weight loss (cachexia) is a complex, multifactorial syndrome that results from a reduction in food intake, a variety of metabolic abnormalities (including hypermetabolism) or more often a combination of the two. Multiple mediator pathways including proinflammatory cytochines, neuroendocrine hormones and tumor specific factors are involved. Therapy requires a multimodal approach that addresses both reduced food intake and metabolic change. Combination treatment such as nutritional support plus metabolic/inflammation modulation with EPA promises improved functional capacity and quality of life. Further research is needed to identify the optimal therapeutic approach in the different clinical settings of patients with cancer induced weight loss. In particular the early appearance of biological alterations associated with cachexia development suggests a potential role for early intervention, beside treatment of the advanced stages of cancer malnutrition.

\section{References}

1. Baracos VE (2006) Cancer-associated cachexia and underlying biological mechanisms. Annu Rev Nutr 26:435-461

2. Barber MD, Ross JA, Voss AC, Tisdale MJ, Fearon KCH (1999) The effect of an oral nutritional supplement enriched with fish oil on weight-loss in patients with pancreatic cancer. Br J Cancer 81:80-86

3. Bossola M, Muscaritoli M, Costelli P, Grieco G, Bonelli G, Pacelli F, Rossi Fanelli F, Doglietto GB, Baccino FM (2003) Increased muscle proteasome activity correlates with disease severity in gastric cancer patients. Ann Surg 237:384-389

4. Colomer R, Moreno-Nogueira JM, Garcia-Luna PP, Garcia Peris P, Garcia-de-Lorenzo A, Zarazaga A, Quecedo L, Del Llano J, Usan L, Casimiro C (2007) n-3 Fatty acids, cancer and cachexia: a systemic review of the letterature. Brit J Nutr 97:823-831

5. Fearon $\mathrm{KCH}$, von Meyenfeldt MF, Moses AGW, van Geenen R, Roy A, Gouma DJ, Giacosa A,Van Gossum A, Bauer J, Barber MD, Aaronson NK, Voss AC, Tisdale MJ (2003) Effect of a protein and energy dense n-3 fatty acid enriched oral supplement on loss of weight and lean tissue in cancer cachexia: a randomised double blind trial. GUT 52:1479-1486

6. Giacosa A, Frascio F, Sukkar SG, Roncella S (1996) Food intake and body composition in cancer cachexia. Nutrition 12:S20-S23

7. Grimm H, Mertes N, Goeters C, Schlotzer E, Mayer K, Grimminger F, Furst P (2006) Improved fatty acid and leukotriene pattern with a novel lipid emulsion in surgical patients. Eur J Nutr 45:55-60

8. Jatoi A (2005) Omega-3 fatty acid supplements for cancer-associated weight loss. Nutr Clin Pract 4:394-349

9. Moses A, Slater C, Preston T, Barber M, Fearon K (2004) Reduced total energy expenditure and physical activityin cachectic patients with pancreatic cancer can be modulated by energy and protein dense oral supplement enriched with n-3 fatty acids. Br J Can 90:996-1002

10. Stehr SN, Heller AR (2006) Omega-3 fatty acid effects on biochemical indices following cancer surgery. Clin Chim Acta 373:1-8

11. Wigmore SJ, Ross JA, Falconer JS, Plester CE, Tisdale MJ, Carter DC, Fearon KCH (1996) The effect of polyunsaturated fatty acids on the progress of cachexia in patients with pancreatic cancer. Nutrition 12:S27-S30 